\title{
The influence of vegetable-oil based polyols on physico-mechanical and thermal properties of polyurethane foams
}

\author{
Aleksandra Badan ${ }^{1, *}$, Tomasz M. Majka ${ }^{1}$ \\ 1 Aleksandra Badan Cracow University of Technology, Department of chemistry and technology of \\ polymers, Warszawska 24, 31155 Cracow Poland; aleksandrabadan@gmail.com \\ 1 Tomasz M. Majka Cracow University of Technology, Department of chemistry and technology of polymers, \\ Warszawska 24, 31155 Cracow Poland; tomasz.majka@pk.edu.pl \\ * Correspondence: aleksandrabadan@gmail.com; Tel.: +48-888-867-093 \\ Received: 24/10/2017
}

\begin{abstract}
Polyurethanes during the last 50 years have become one of the most developing polymers and it is almost impossible to find an industry field, where they are not used. This term concerns a wide range of materials, both expanded and non-expanded products. PUs are widely used in many applications as foams (flexible, semi-flexible and rigid foams), elastomers, adhesives, fibers and obtained by the exothermic reaction of an oligomeric polyol (the substance which contains at least two hydroxyl groups) and polyfunctional isocyanates. PU foams are considered to be one of the most efficient materials for insulation with many desirable properties (very low conductivity, low density and water absorption, dimensional stability and high eco-efficiency index to save energy). Nowadays, rigid polyurethane foams are synthesized using vegetable-oil based polyols, which is connected to their abundance and economy. What is more, materials synthesized from renewable resources can almost fully replace their petrochemical analogs. Several types of vegetable oils have been already used, such as soy bean oil, palm oil, linseed oil and sunflower oil. Such oils are characterized by low amount of functional groups, however present in the structure unsaturated bonds can be successfully converted into hydroxyl groups. The great possibility is using waste cooking oil to synthesize polyol, but the biggest problem is low number of hydroxyl value and contaminations from food. It is necessary to check the influence of various polyol systems on physical, mechanical and thermal insulation properties, as well as on the cellular structure.
\end{abstract}

Keywords: polyurethanes, vegetable oils, biobased polyols

\section{Introduction}

Polyurethanes (PUs) have actually very short history, but very fast became one of the most developing group of polymers. Polyurethane is a material widely used in many different applications, such as foams, elastomers, adhesives or fibers and so on. Additionally, they are used in some specialty applications (biomedical surgery). They are clearly a great research subject due to their mechanical, physical and chemical properties. Polyurethanes are obtained by the reaction of an oligomeric polyol and diisocyanate. The structure and properties of polyol have a great influence on the properties of the resulting polymer [1]. In addition, to control reactions and properties of PU foams, many additives such as catalysts, surfactants, fillers, chain extenders and flame retardants are added [2].

Nowadays, mostly petrochemical raw materials are used to produce polyurethanes. It has changed due to the uncertainty in terms of price and availability of petroleum. What is more, there are tendencies to develop a sustainable chemistry and use of renewable resources. This is the reason 
why chemical industry has paid their attention to the production of biobased polyols, mainly synthesized from vegetable oils [3]. It is important to realize that biobased product is not necessarily a biodegradable material, but only a material made from renewable resources [1-3].

Most of the polyols used for polyurethane synthesis are polyether polyols $(75 \%)$, which are obtained by the reaction between a 'starter' polyol and an alkylene oxide. Typical industrial starters are ethylene glycol, glycerol, sorbitol, sucrose, water, ethylenediamine and diaminotoluene. The most important for synthesis of polyether polyols is glycerol which is produced by the hydrolysis of natural triglycerides, from vegetable or animal resources [3]. Long-chain polyether polyols usually have on $\mathrm{OH}$ number below $100 \mathrm{mg} \mathrm{KOH} / \mathrm{g}$ and around 2-3 hydroxyl groups/mol, and molecular weights of 2000-10000 daltons. They are mainly used for flexible foams. On the contrary, short-chain polyether polyols usually have an $\mathrm{OH}$ number of $200 \mathrm{mg} \mathrm{KOH} / \mathrm{g}$, high functionality (3-8 hydroxyl groups/mol) and molecular weight about 300-1000 daltons. Using short-chain polyether polyols leads to a rigid crosslinked polyurethane. Polyester polyols are also used $(25 \%)$, resulting from step growth polycondensation between dicarboxylic acid and polyol in excess [3-4]. Unfortunately, a $100 \%$ biobased polyurethane is not available yet because of the unsatisfactory properties. So far researchers have developed materials that contains about $50 \%$ biobased components with no worse properties than petrobased polyurethanes [5].

Depending on the application the renewable content of commercially available bio-based polyols varies between $30-100 \%$. As a consequence the renewable content of bio-based substract in PU also varies around 8-70\% (Table 1) [6].

Table 1. Renewable content of commercial available bio-based polyols and PURs

\begin{tabular}{ccc}
\hline $\begin{array}{c}\text { Renewable source for } \\
\text { polyols }\end{array}$ & Bio-content in polyols & Bio-content in PUR \\
\hline sucrose & $\leq 30 \%$ & $<8 \%$ (rigid foam) \\
soybean & $40-100 \%$ & $5-60 \%$ (rigid\&flexible \\
foam) \\
castor oil & $30-100 \%$ & $22-70 \%$ (flexible\&rigid \\
foam) \\
sunflower oil \\
corn sugar
\end{tabular}

\section{Synthesis of bio-polyols}

Vegetable oils come from many various plants, such as soybean, palm, rapeseed and so on and contain mainly triglycerides molecules, where the three hydroxyl functions of glycerin are esterified with fatty acids, which could be saturated or unsaturated [3]. The most important are unsaturated oils, which double bonds can be transformed into hydroxyl groups [3,7].

There are four methods that could be used to prepare polyols from vegetable oils (Table 2) [8]:

- oxidation and epoxidation;

- esterification;

- hydroformylation;

- ozonolysis.

Table 2. Methods of preparing polyols from vegetable oils

\begin{tabular}{l|l} 
Name of reaction & Scheme
\end{tabular}




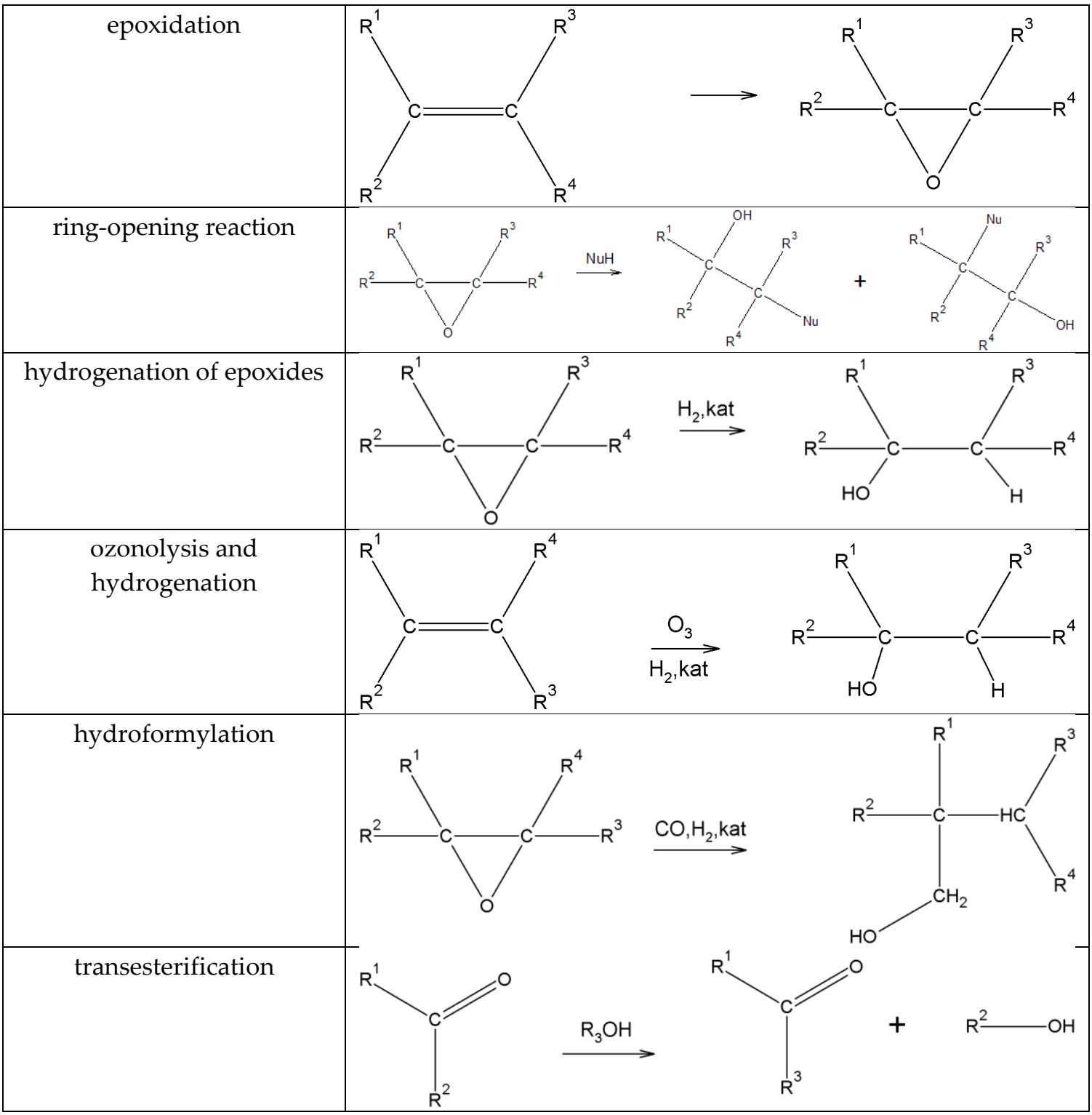

By the direct action of hydrogen peroxide on double bonds and then ring opening by using alcohols or inorganic acids a high degree of hydroxylation may be incorporated into polyols [3-4]. Vegetable oils that are characterized by a higher degree of unsaturation always produce polyols with much higher hydroxyl functionalities, which results in higher crosslinked density PUs[ 4].

Castor oil, derived from the bean contains $87-90 \%$ ricinoleic acid (fatty acid triglyceride) and it can be transesterified with a polyhydroxylated compound such as glycerine in order to obtain higher hydroxyl functionality. Hydroformylation route consists of two steps. In the first one, vegetable oils react with syngas- $\mathrm{CO}$ and $\mathrm{H}_{2}$ in the presence of rhodium, which is a better catalyst (almost $100 \%$ efficiency) or cobalt carbonyls (about $60 \%$ efficiency). This reaction introduces aldehyde groups, which are then converted to hydroxyls in the second step (hydrogenation). Polyols obtained in this route have longer network chains than the polyols prepared by epoxidation due to an extra carbon at every double bond. Ozonolysis of vegetable oil typically involves two main steps: formation of ozonide at the unsaturation sites of vegetable oils and its decomposition into aldehyde and carboxylic acid. The second step is reduction of aldehyde into alcohol (with a catalyst). Ozonolysis of soybean oils results in triols, triglyceride diols and some mono-ols [1,7-8].

A special vegetable oil is castor oil, extracted from the seeds of the plant Ricinus communis, which is a triglyceride of ricinoleic acid and contains naturally occurring hydroxyl groups ( Figure 1). 


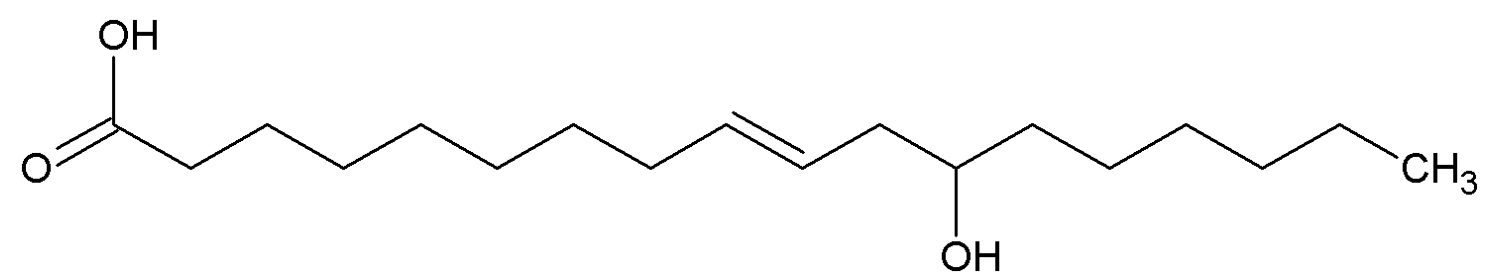

Figure 1. Chemical structure of major fatty acid in castor oil

Natural castor oil has a functionality of around $2.7 \mathrm{OH}$ groups $/ \mathrm{mol}$ and an hydroxyl number of around $160 \mathrm{mg} \mathrm{KOH} / \mathrm{g}$ and is used in many various applications, such as: coatings, rigid foams, adhesives, thermoplastic elastomers, flexible foams and so on. On the other side, castor oil has some major disadvantages: low functionality and low reactivity due to the secondary hydroxyl groups. It is possible to use two major modification to improve the properties and applicability of castor oil-based polyols for producing PUs. The first one is the transesterification/amidation and the other one is the alkoxylation using its hydroxyl groups and both lead to new polyols which can be used to obtain rigid polyurethane foams with good physico-mechanical properties. Castor oil used solo leads to semi-flexible to semi-rigid PU foams, but by mixing it with polyols such as glycerol a higher hydroxyl number of polyol is obtained [4,7].

\section{Properties of PU foams obtained by using bio-based polyols}

It is known that most of the conducted researches concerned soybean oil, which has become one of the most popular and used oils of the recent years.

A.A. Beltran et all have conducted interesting researches which concern using soy-based polyols to obtain rigid polyurethane foams. As an isocyanate they used polymeric MDI (A side) and as a B ingredient they mixed polyols that constitutes 100 parts for the formulation of the rest of compounds (catalyst, surfactant, foaming agent). The polyol mix included Voranol 446, Voranol 640 and soy-based polyols with hydroxyl numbers of 120 from ethanol and $331 \mathrm{mg} \mathrm{KOH} / \mathrm{g}$ from ethylene glycol. Both used polyols were prepared through an in situ epoxidation of the soybean oil. The soybean oil polyol percentage in the mix varied between 20 and 30\% for a total of 4 blocks of rigid foam, two for each type of oleochemical polyol. Rigid PU foams are mainly used for thermal insulation and the most optimal density value between $40-60 \mathrm{~kg} / \mathrm{m}^{3}$. When it comes to best possible compressive strength, for densities of $30 \mathrm{~kg} / \mathrm{m}^{3}$ it is in $100-150 \mathrm{kPa}$. Obtained values (Table 3) indicate that these results validate the use of the produced foams in the polymeric industry. The author marks that produced foams can be especially used for insulation in refrigeration and cooling appliances [5].

Table 3. Properties for obtained PU foams

\begin{tabular}{ccccc}
\hline $\begin{array}{c}\text { Soybean based } \\
\text { polyol }\end{array}$ & Block & $\%$ & $\begin{array}{c}\text { Compressive } \\
\text { strength [kPa] }\end{array}$ & $\begin{array}{c}\text { Conductivity } \\
\text { [W/mK] }\end{array}$ \\
\hline from ethanol & 1 & 20 & 141.3 & 0.0221 \\
& 2 & 30 & 131.3 & 0.0246 \\
from ethylene & 3 & 20 & 130.5 & 0.0218 \\
glycol & 4 & 30 & 103.5 & 0.0264 \\
\hline
\end{tabular}

Table 2 also presents conductivity of different PU foams. The characteristics of the obtained materials are comparable with the commercial ones [5].

Yusuf A.K. et all have also checked an influence of castor oil polyols on mechanical properties of rigid PU foams. They used two formulations: isocyanate/polyol $(\mathrm{NCO} / \mathrm{OH})$ ratios of $1 / 2$ and $1 / 1$ and one shot method. The glycerolized castor oil contained varying concentrations $(10-60 \%)$ of the modifier and other ingredients were mixture of 2,4- and 2,6- toluene diisocyanate at room temperature, catalyst, physical blowing agent (methylene chloride) and surfactant (silicone oil). Hydroxyl number range for the modified castor oil polyols was $168-320 \mathrm{mgKOH} / \mathrm{g}$. Compressive 
strength of obtained PU foams increased steadily up to about $30 \mathrm{wt} \%$ of modifier concentration, followed by a sharp steep rise up to $60 \%$ (foams prepared using formulation II). The highest showed compressive strength value up to $450 \mathrm{KN} / \mathrm{m}^{2}$. Higher hydroxyl functionality in polyol results in increased crosslinking reactions and therefore in formation of inter-chain network. This structure can results in increased density and rigidity in foam structure, which makes foam harder to compress [9].

Researches from Cracow University of Technology used bio-polyol based on rapeseed oil to produce flexible PU foams. One of the aims was to check the influence of bio-polyols production scale on selected mechanical and physical properties. However, it was observed that it has no significant impact on flexible PU foams properties (density, hardness, hysteresis, support factor and resilience), but it turned out that different values of bio-polyol has a great influence on the foams properties compared to the references foams which were not modified with the bio-polyols. PU formulations for the periodical synthesis are shown in Table 4 [10].

Table 4. The characteristics of applied bio-polyols and PUR formulation

\begin{tabular}{cccccc}
\hline $\begin{array}{c}\text { polyol } \\
\text { symbol }\end{array}$ & $\begin{array}{c}\text { LOH } \\
\text { [mgKOH/g] }\end{array}$ & foam symbol & $\begin{array}{c}\text { content of } \\
\text { petrochemical } \\
\text { polyol [g] }\end{array}$ & $\begin{array}{c}\text { content of } \\
\text { rapeseed } \\
\text { oil-based } \\
\text { polyol [g] }\end{array}$ & $\begin{array}{c}\text { content of } \\
\text { catalysts [g] }\end{array}$ \\
\hline F3600 & 48 & REF1P & 100 & 0 & 0.46 \\
RziP52 & 52 & RziP52P & 80 & 20 & 1.13 \\
RziP58 & 58 & RziP58P & 80 & 20 & 1.00 \\
RziP72 & 72 & RziP72P & 80 & 20 & 1.13 \\
RziP75 & 75 & RziP75P & 80 & 20 & 1.00 \\
RziP84 & 84 & RziP84P & 80 & 20 & 1.00 \\
\hline
\end{tabular}

Figure 2 shows the effect of polyol type on apparent density and hardness at $40 \%$ deformation of foams which were obtained with periodical method. It was observed that bio-polyol addition reduces the density of the obtained materials. It is connected to the increase of a catalyst amount [10].

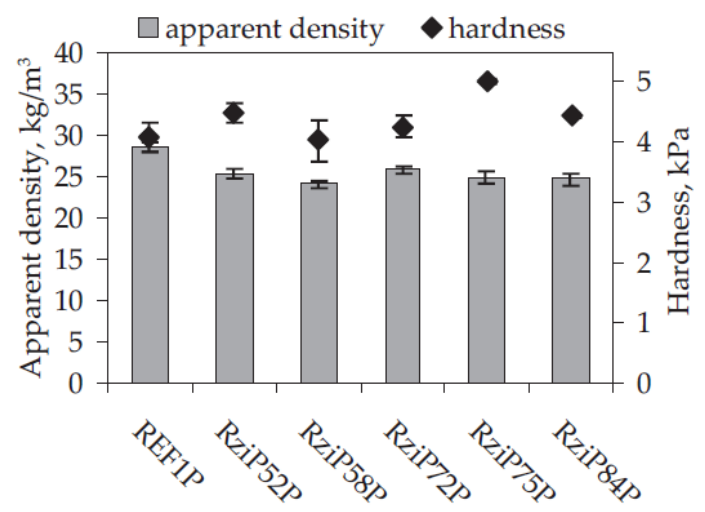

Figure 2. Apparent density and hardness at $40 \%$ deformation of foams obtained using different bio-polyols

The addition of a bio-polyol to PUR formulation increases the hardness at $40 \%$ deformation in a majority of foams, in comparison to the reference foam despite the apparent density reduction, what can be caused by the higher content of hard segments and difference in crosslinking density. The results of the conducted researches confirmed that the modification of polyurethane systems with rapeseed oil-based polyols can give beneficial effects [10].

Syuhada Mohd Tahir et all carried out studies to determine the potential of waste cooking oil in preparation of rigid PU foam. First, the raw waste cooking oil was filtered and adsorbed by using 
sugarcane bagasse activated carbon to purify the oil. Next, the transesterification reaction was used to synthesize polyol and then the obtained polyol was mixed with other chemicals to form PU rigid foam. The density and compressive strength of 60:54:90:40 of glycerol:water:polyol:amine polyurethane foam are $277.7 \mathrm{~kg} / \mathrm{m}^{3}$ and $0.10 \mathrm{MPa}$. The study shows that waste cooking oils can be used in production of rigid PU foams with obtaining a satisfactory properties. The similarities in organic structure of waste cooking oil to vegetables oil make it a perfect starting material [11].

\section{Future perspectives}

Vegetable oils are becoming more and more popular in polyols synthesis due to their properties which let change them into the valuable polyols that can be used to produce not only PU foams but also elastomers, coatings and rigid plastics. Every material is characterized by the same or even better properties as products from the petroleum-based substracts. It is possible to obtain polyols with different reactivities, functionalities, molecular weights and other important properties. It is a great potential to change totally the world of PU foams, but vegetable oils and their derivatives still face challenges which are hard to solve, including costs of obtaining. However, advanced technologies are promising and the future of bio-based polyols looks very bright $[1,12]$.

Author Contributions: Aleksandra Badan performed the experiments and analyzed the data; Aleksandra Badan and Tomasz M. Majka wrote the paper.

Conflicts of Interest: The authors declare no conflict of interest. The founding sponsors had no role in the design of the study; in the collection, analyses, or interpretation of data; in the writing of the manuscript, and in the decision to publish the results.

\section{References}

1. Eaves David, Handbook of Polymer Foams, Rapra Technology Limited, Shawbury, UK, 2004, pp.55-60.

2. Chuayjuljit S., Maungchareon A., Saravari O., Preparation and Properties of Palm Oil-Based Rigid Polyurethane Nanocomposite Foams, Sage, 2008, 218-220, 10.1177/0731684408096949.

3. Ionescu Michail, Chemistry and Technology of Polyols for Polyurethanes, Rapra Technology Limited, Shawbury, UK, 2005, pp. 443-446.

4. Li Yebo, Luo Xiolan, Hu Shengjun, Bio-based Polyols and Polyurethanes, Springer, New York, 2015, pp.15-33

5. A.A.Beltrán, L.A. Boyacá, Production of Rigid Polyurethane Foams from Soy-based Polyols, Latin American Applied Research, 2009, pp. 76-78.

6. Li Shen, Juliane Haufe, Martin K. Patel, Product overview and market projection of emerging bio-based plastics, Group Science, Technology and Society, Copernicus Institute for Sustainable Development and Innovation Utrecht University, 2009, 141-153.

7. Guo A., Demydov D., Zhang W., Petrovic Z.S., Polyols and polyurethanes from hydroformylation of soybean oil, Journal of Polymers and the Environment, United States, 2002, Volume 10, 49-52, 10.1023/A:1021022123733.

8. Desroches M., Escouvois M., Auvergne R., Caillol S., Boutevin B., From Vegetable Oils to Polyurethanes: Synthetic Routes to Polyols and Moin Industrial Products, Polymer Reviews, Taylor\&Francis, 2012, 52(1), pp.38.,10.1080/15583724.2011.640443.

9. A.K. Yusuf, P.A.P. Mamza, A.S. Ahmed, U. Agunwa, Physico-Mechanical Properties of Rigid Polyurethane Foams Synthesized From Modified Castor Oil Polyols, International Journal of Scientific and Research Publications, Volume 6, Issue 7,548-554, 2016.

10. Malewska E., Bąk Sz., Kurańska M., Prociak A., The effect of various rapeseed oil-based polyols on selected properties of flexible polyurethane foams, Polimery, 2016, 61, 801-803, dx.doi.org/10.14314/polimery.2016.799.

11. Syuhada Mohd Tahir, Wan Norfir daus Wan Salleh, Nur Syahamatun Nor Hadid, Nor Fatihah Enderus, Nurul Aina Ismail, Synthesis of Waste Cooking Oil-Based Polyol Using Sugarcane Bagasse Activated Carbon and Tranesterification Reaction for Rigid Polyurethane Foam, Materials Science Forum, Vol.846, pp.690-696, 2015, 10.4028/www.scientific.net/MSF.846.690.

12. Guo A., Zhang W., Petrovic Z.S., Structure-property relationships in polyurethanes derived from soybean oil, Springer, 2005, 10.1007/s10853-006-0310-6. 
(C) 2017 by the authors. Submitted for possible open access publication under the terms and conditions of the Creative Commons Attribution (CC BY) license (http://creativecommons.org/licenses/by/4.0/). 